\title{
El palacio fortificado de Ibn Hafṣūn y sus ḥuṣūn-abwāab. La supuesta edilicia ḥafṣūní y los modelos orientales en el occidente malagueño
}

The fortified palace of Ibn Hafșūn and its ḥuṣūn-abwāb. The supposed hafṣuní architecture and the oriental models in western Malaga

\section{Francisco Marmolejo Cantos}

Universidad de Málaga, Málaga, Spain, arqueologiacoin@gmail.com

\begin{abstract}
New interpretative approaches are raised about hafșūní architecture based on the archeological data in the medieval city of Bobastro and its most immediate castles, all located in the limits of the municipal terms of Ardales and Alora, to the northwest from the capital of Malaga. We focus our attention on the palatine complex built by Ibn Ḥafșūn during the Umayyad emirate and we present numerous nearby fortress, which has allowed us to first approach the knowledge of the defensive system that protected the medieval city. Among the recent evidence of the hafșūní palace, as a result of this study, structural and ornamental elements are discovered that derive from the classical tradition, but they are unknown by local structures and must respond to the influence of the Syrian-Byzantine model.
\end{abstract}

Keywords: Umayyad emirate, al-Andalus, architecture, archaeology.

\section{Nociones previas}

Bobastro fue una ciudad emiral de cultura árabe que vivió su mayor esplendor político, social y económico en el tránsito al siglo X. Residencia de los Banū Hafșūn y de los disidentes que se unieron a su causa, y sede de la revuelta que se enfrentó a los soberanos omeyas de Córdoba durante cincuenta años. Creada de la nada para ejercer el poder y representarlo, tenemos que convenir con M. Acién (1997, p. 85) en "que fue una empresa de Ibn Hafșūn, coincidiendo varias fuentes en citarlo como ŷabal (monte) en el momento de cogerlo como refugio", todo lo cual viene siendo refrendado por el registro cerámico. No obstante, los orígenes de Bobastro no están asentados sobre criterios cronológicos fiables; dado que no existen secuencias estratigráficas publicadas sobre el yacimiento, algo que lamentar, pese a las excavaciones arqueológicas recientes, donde parece imperar la arqueología monumental en detrimento de cualquier avance científico.

La celeridad que debió alcanzar el proceso urbano se puede rastrear en las fuentes textuales, cuando relatan que Ibn Hafṣūn erigió una mezquita aljama al principio de su rebelión y descartó, por tanto, ampliar la primitiva mezquita fundacional (Muqtabis, V, pp. 168 y 216). En este preciso momento pudo iniciarse su proyecto de ciudad, no concebida como embrionaria de un Estado, más bien como soporte de su legitimidad, especialmente entre sus primeros seguidores de mayoría musulmana, que habían llegado a 


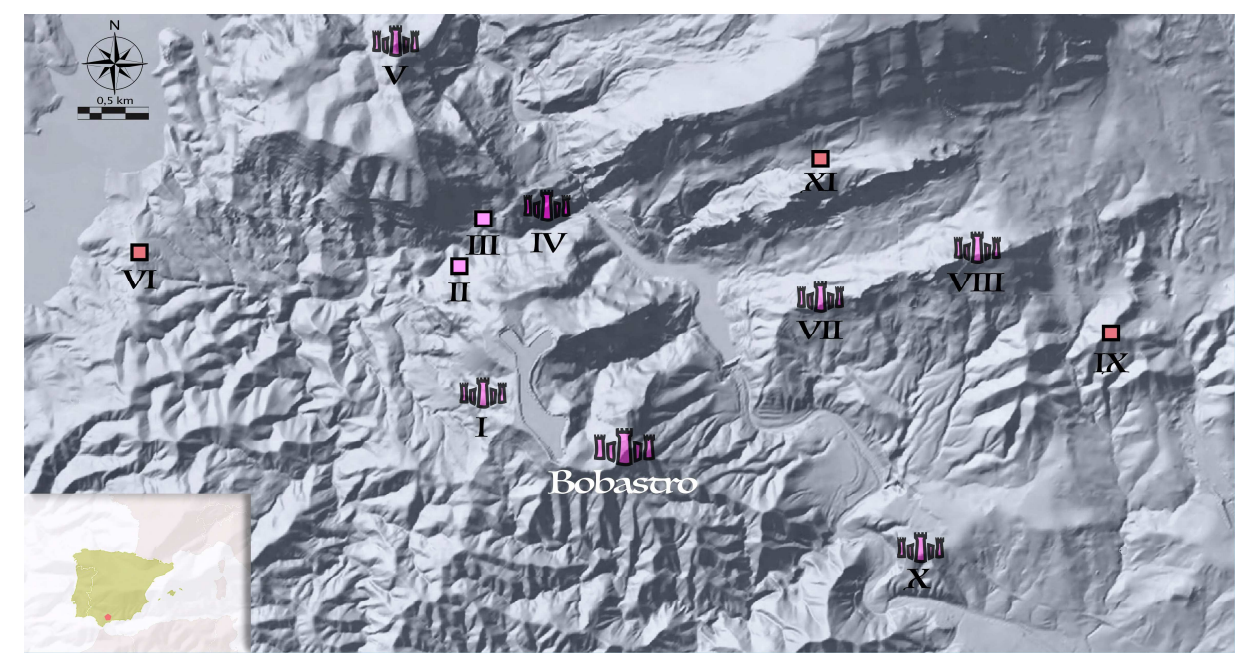

Fig. 1. Localización geográfica de Bobastro (Mesas de Villaverde) y enclaves más inmediatos: 1) Complejo basílica semirrupestre; 2) Peñón del Moro; 3) Ermita de Villaverde; 4) Castillón de los Gaitanes/Cerro Cristo; 5) Pico del Convento; 6) Cerro de las Atalayas; 7) Peñón de la Almona; 8) Cerro de Hornos; 9) Cerro cortijo de la Teja; 10) Castillejo de Mombicha; 11) Pedreras.

Bobastro para asentarse en la incipiente madina.

De aquel Bobastro citado en la cronística árabe, hoy quedan vestigios de una ciudad fortificada en altura con un tejido urbano jerarquizado, cristianizado y militarizado, donde los edificios más representativos se alzan sobre la cota máxima y son visibles desde cualquier ángulo de la ciudad. Se conservan sus vestigios sobre una prominente mesa de bordes escarpados en los confines de los términos de Ardales y Álora, donde confluyen tres de los principales ríos del occidente malagueño (Guadalhorce, Guadalteba y Turón).

Hoy es una de las mayores superficies arqueológicas arrasadas de la España del siglo XX, más del $60 \%$ del total fue destruido o alterado tras la construcción del embalse Tajo de la Encantada por la compañía eléctrica Sevillana hacia 1974. Con todo ello, aún perviven los restos del palacio que levantaron los Banū Ḥafșūn y reconstruyó 'Abd al-Raḥmān III (siglo X), sirviendo como último refugio a varios califas hammūdíes (siglo XI).

\section{Espacio áulico}

El complejo palatino de Bobastro levantado por Ibn Ḥafșūn durante el emirato omeya aglutina los edificios más emblemáticos y representativos de la madina. Se encuentra topográficamente aislado del resto de la ciudad y encerrado en el interior de la alcazaba, conservando cierto aspecto de ciudadela. Se compone de un palacio fortificado envuelto por otro recinto con torres cuadradas, perceptibles en el frente oeste, a lo que habremos de añadir una alcazaba inédita que va bordeando la doble cumbre de los cerros del Castillón y Tintilla, donde también se inserta una iglesia basilical recientemente excavada con motivo del vallado de la parcela (Martínez, 2012).

La naturaleza palatina del complejo se desprende de la riqueza de los conjuntos cerámicos y los elementos arquitectónicos y ornamentales que se vienen documentando desde el siglo XIX, lo cual permite hablar de un espacio de carácter áulico, adecuado al gusto y prestigio social tanto de los señores locales como de los representantes omeyas que se instalaron en sus salones y dependencias. Hoy quedan los vestigios de un edificio monumentalizado que va más allá de la arquitectura doméstica y poliorcética altomedieval, pues aquí se labran sillares, se esculpen mármoles, se pavimentan suelos, se decoran paredes y se canalizan aguas bajo el subsuelo. 


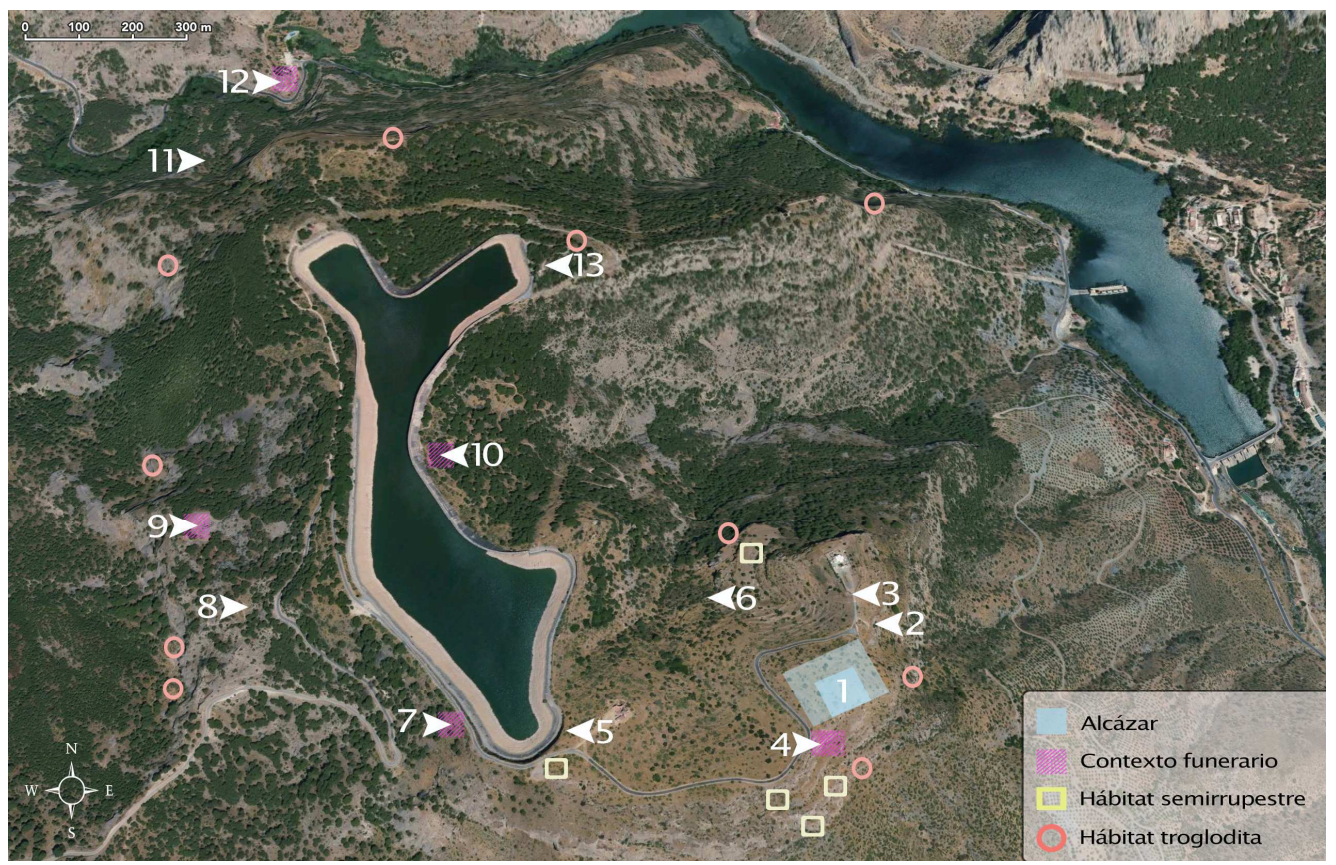

Fig. 2. Vista aérea del complejo arqueológico: 1) Alcázar; 2) Murallas de la alcazaba; 3 ) Iglesia basilical; 4) Contexto funerario infantil; 5) Edificio oficial; 6) Oratorio semirrupestre; 7) Necrópolis; 8) Murallas de hiṣn-puerta; 9) Iglesia semirrupestre; 10) Necrópolis; 11) Peñón del Moro; 12) Necrópolis de Villaverde; 13) Estructura de torre.

La residencia de los Banū Hafṣun era un complejo militar y palaciego que ocupaba la parte central y superior del alcázar, elemento fundamental dentro de la organización espacial de la ciudad, cuya configuración viene dada por la peculiar topografía del yacimiento. Únicamente en este sector se llevaron a cabo excavaciones en los años veinte del siglo pasado (Mergelina, 1927); por lo cual carecemos de registro estratigráfico en nuestros días (Fig. 3). Un segundo recinto de planta trapezoidal envuelve el palacio, delimitando un espacio subdividido en cuatro zonas aterrazadas. Por lo demás, desconocemos las edificaciones incluidas en los sectores periféricos, con la salvedad de una posible entrada en rampa a la zona palaciega (Mergelina, 1927, p. 23).

Del recinto exterior inédito, que hemos denominado alcazaba, se evidencian restos de mampostería y sillería en la falda $\mathrm{S}$ del Castillón y en la vertiente este del cerro Tintilla. Dentro de su perímetro queda inserta la iglesia basilical, la cual, a nuestro modo de ver, puede caracterizar- se como "iglesia palatina", formando parte del conjunto áulico de Ibn Ḥafșūn, ello atendiendo a su fábrica, su posición topográfica, su inmediatez al alcázar y sus reducidas dimensiones, apropiadas para dar cabida a los estamentos religiosos y administrativos. ${ }^{1}$

De las fuentes históricas se desprenden cuatro posibles intervenciones edilicias sobre la fortaleza de Bobastro: la de al-Taŷūbī, la de Ibn Ḥafșūn, la de Abd al-Raḥmān III y posiblemente la de los hammūdíes. Disponemos de datos para pensar que son obras oficiales que se suceden en escaso margen de tiempo y que posiblemente replican modelos de influencia omeya. De ahí la complejidad para diferenciar materiales y aparejos sin un estudio previo que tenga en cuenta las variaciones métricas de los sillares y la composición de los morteros, pues la lectura de los alzados se presenta muy limitada. En línea con lo expuesto, Mergelina documentó sólo tres momentos constructivos en el palacio por él excavado, que compartimos plenamente en función del aparejo y la posición estratigráfica 
de algunos elementos arquitectónicos, estructurales y ornamentales. ${ }^{2}$

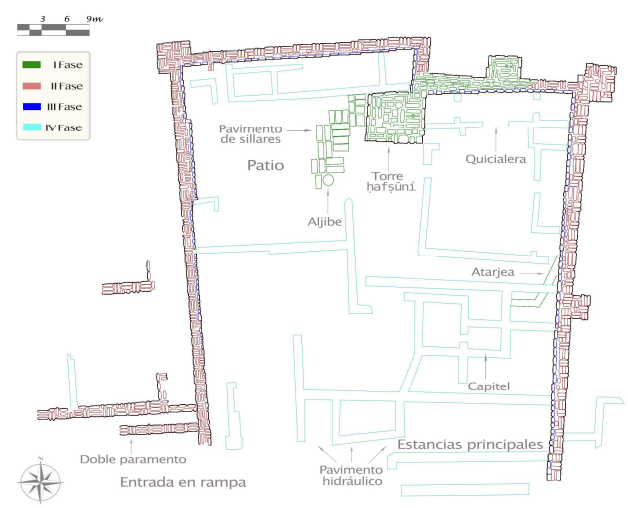

Fig. 3. Plano del sector palaciego del alcázar con sus fases edilicias, basado en el publicado por Mergelina.

\subsection{Detalles ornamentales}

En nuestro empeño por definir algunos rasgos constructivos de esa supuesta edilicia ḥafșūní, podemos destacar en el plano ornamental la existencia de capiteles de mármol con decoración vegetal y collarino sogueado, de claro influjo bizantino, además de columnas cilíndricas de fuste helicoidal y de columnillas de tambor talladas en calcarenita (Fig. 4). Otro de los rasgos que adscribimos al primer palacio de Ibn Hafșūn, por ser obra de sus talleres y posiblemente de influencia omeya, son los pavimentos hidráulicos pintados a la almagra para las estancias de interior y los pavimentos de sillares de piedra calcarenita para los espacios abiertos al exterior (Fig. 3).

Entre los derrumbes, más allá de los sillares y quicialeras, se advierten muchas piezas pétreas talladas de la más diversa tipología y función. Se aprecian posibles dovelas pertenecientes a arcos, cornisas y baquetones tallados en calcarenita y otros elementos moldurados con junquillos.

En el ala sudeste de la zona residencial también se observan fragmentos de enlucido con restos de pinturas parietales, que hacemos corresponder con los zócalos que pudieron recubrir las estancias más nobles. Se evidencian morteros de cal y arena con incisiones trazadas al fresco, posiblemente usando reglas, sobre las que se aplican finas pinceladas de pintura a la almagra.

Durante la excavación dirigida por Mergelina se descubrió una quicialera de piedra con cilindro horizontal en su vuelo, típica del siglo $\mathrm{X}, \mathrm{y}$ reutilizada como umbral de puerta en la última fase constructiva. En lo que a nosotros interesa, también se halló un ejemplar de capitel compuesto con detalles estilísticos que permiten su datación y su posible adscripción al palacio erigido por 'Abd al-Raḥmān III. Presenta dos rangos de hojas, un equino bien definido y volutas discoidales, cuya espiral se desarrolla en banda entre el equino y el ábaco, éste decorado con palmetas de puntas rectas, de brazos curvos y sensiblemente más alto que los tipos clásicos (Mergelina, 1927, p. 23; Bermúdez Cano, 2004, p. 270).
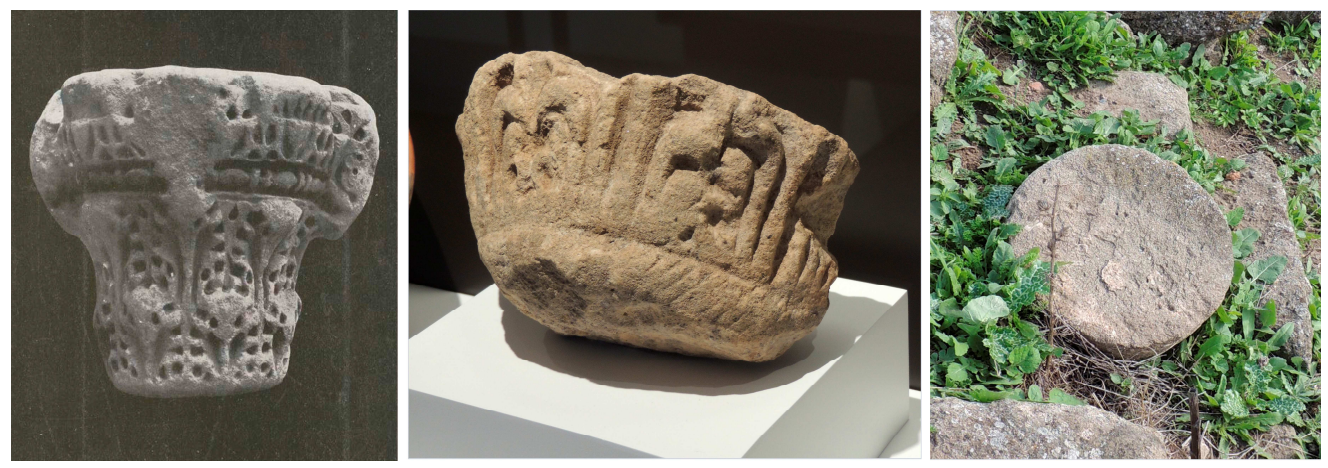

Fig. 4. Capitel compuesto omeya, capitel emiral con sogueado de influjo bizantino y tambor cilíndrico de columnilla (Autor). 


\subsection{Obra de Ibn Ḥafṣūn}

De lo poco que conocemos, la arquitectura que desarrolla Ibn Hafșūn en sus edificios representativos no tiene unos rasgos propios y específicos, por lo que tampoco vemos apropiado emplear el término o calificativo hafșūní, y mucho menos como una arquitectura contrapuesta y diferenciada de la omeya, que es la que pretende emular y de la que toma todas sus influencias.

Con todo, Ibn Hafșūn traerá una arquitectura nueva o si se quiere olvidada durante siglos en la zona malagueña, con un programa constructivo de rasgos orientales, que se verá materializado por talleres foráneos de procedencia desconocida. Sustituyen la mampostería por la sillería y recuperan las canteras y caleras, lo que supone toda una ruptura con lo conocido hasta entonces en la algarbía de Málaga.

Por lo que se observa, la sillería queda reservada para las edificaciones oficiales y representativas. Su puesta en obra emplea recalzos, debido a la irregularidad de las piezas, así como morteros de barro o de cal, lo que quizá nos esté indicando distintas etapas edilicias por parte de los talleres de Ibn Hafșūn.

Su proyecto de construcción más ambicioso fue el complejo palatino que levantó sobre el cerro del Castillón (Fig. 3, fase I). De la obra de sus talleres, se distinguen los cimientos de una gran torre dominando el ala norte del área residencial y las primeras hiladas de algunos lienzos de sillares aparejados a soga, insertando algunos perpiaños a tizón. Junto a la estructura de torre, se descubrió un espacio abierto cuadrangular, con aljibe y pavimento de sillares de extraña disposición, que creemos puede tratarse de un patio (Mergelina, 1927, p. 21). Su disposición en planta, desplazado a la crujía occidental, se aparta de los edificios áulicos andalusíes estudiados hasta el momento (Torres, 1958; Navarro Palazón, 2005; Vallejo Triano, 2010); ello a menos que existiera otro patio en el extremo oriental, donde Mergelina llegó a documentar restos de una atarjea. Por razones obvias, nos inclinamos por pensar que esta infraestructura hidráulica pudiera estar vinculada con una letrina, pues se inserta en las habitaciones anejas a lo que debió ser el salón del ala sudeste, posible- mente la pieza más singular del complejo, perceptible con meridiana claridad en el pavimento hidráulico que llegó a excavar Mergelina (1927, p. 22). La atarjea de desagüe se descubrió colmatada de producciones cerámicas vidriadas de carácter áulico (loza dorada temprana y otras decoradas con vedrío amarillo, verdemanganeso, cobalto azul, cuerda seca parcial...), fechables todas en el siglo $X$, momento en el que pudo perder su funcionalidad principal, quedando para verter en su interior desechos cerámicos. Debe corresponderse ésta con una fase de abandono del primer sistema de aguas residuales tras la reconstrucción del complejo palaciego.

\subsection{Obra de 'Abd al-Rahmān III}

La fábrica del emir en Bobastro es el mejor precedente de la arquitectura áulica que está por venir, la de Madīnat al-Zahrā'. Los elementos arquitectónicos y ornamentales que conocemos de esta fase omeya son propiamente de época emiral, anteriores a la estandarización de los modelos que surgen y se desarrollan tras la fundación del Califato, lo que es patente no sólo en el aparejo y módulo de sillares, sino también en el capitel compuesto hallado en las excavaciones y conservado hoy en el MAN (Mergelina, 1927, p. 23); todo en consonancia con los textos históricos que nos han llegado, pues la obra omeya se inicia tras la caída de Bobastro en 928, con la pretensión de reconstruir el alcázar ḥafșūní arrasado.

La fábrica cordobesa es la más perceptible entre los restos que quedan del complejo palaciego, aun conservándose poco más que las hiladas inferiores de los muros perimetrales (Fig. 3, fase II). El conjunto del edificio muestra una planta ligeramente rectangular, con contrafuertes exteriores para refuerzo de los muros del frente $\mathrm{E}$, en los que se emplean sillares de calcarenita trabados con mortero de cal, alternando dos tizones por cada soga, aunque es frecuente encontrar a veces uno sólo y otras tres. En este punto, todo hace indicar que se acometió la reconstrucción íntegra del espacio áulico, claro indicio de que fue arrasado, reaprovechándose parte de un lienzo y dos torres del primitivo palacio en la fachada norte, así como otras muchas estructuras 
a nivel de cimentación. Su intervención edilicia es única en la zona por su excelente fábrica, mucho más refinada que la de Ibn Ḥafșūn, y se percibe no sólo en la cuidadosa labra de sus sillares con más homogeneidad en el módulo, sino también en su puesta en obra, con perfectas hiladas horizontales y menor número de calzos, empleando un mortero de cal de excelente calidad.

De lo más notable que se conserva en el complejo arquitectónico es la rampa de acceso por el flanco suroeste a la zona residencial, delimitada por una potente estructura escalonada de doble paramento, con muros externos de sillares de calcarenita y conglomerado $(78 \times 60 \times 20 \mathrm{~cm})$ y núcleo interno relleno de mampostería. Los cajones se conforman con grandes sillares dispuestos a tabla, alternando tizones, algunos marcando el grueso del muro (Fig. 3). Más allá de este singular aparejo, desconocemos su desarrollo en altura y la técnica empleada; aunque se asemeja a los documentados en Córdoba en contextos emirales (León-Muñoz, 2018), por lo que podríamos adscribir esta obra al palacio erigido por el emir.

La relación estratigráfica entre las dos primeras fases se hace evidente en la superposición de fábricas de la torre angular suroeste del alcázar, observada también por Pedro Gurriarán (2004, p. 303) en la torre noroeste, donde se diferencia el aparejo cordobés de sogas y tizones descansando sobre la sillería ḥafṣūní.

La fase III se aprecia en los muros perimetrales internos que cierran el recinto palaciego, que no fueron trabados al paramento externo, empleando para su fábrica sillares irregulares de pequeño formato, aparejados a soga y empleando un mortero de abundante cal, con un llagueado grueso que queda enrasado (Fig. 3, fase III). De la estratigrafía muraria se deduce que la compartimentación interna y la distribución espacial del palacio pertenecen a su última fase constructiva (Fig. 3, fase IV), pues ésta se adosa a la anterior y reutiliza elementos que caben adscribir estilísticamente a la edilicia desarrollada por Abd alRaḥmān III (capitel compuesto y quicialera omeya). No tenemos evidencias arqueológicas para datar con rigor estas últimas obras, tal vez, auspiciadas por los califas ḥammūdíes que trasladaron allí su corte en el siglo XI.

Desde un enfoque arqueológico, el edificio pudo mantenerse en uso hasta el siglo XII, a juzgar por los materiales cerámicos diseminados por la caída $\mathrm{S}$ del cerro, donde se evidencian las producciones más tardías: ataifores estampillados sobre cubierta vítrea melada, entremezclados con los característicos vidriados en verde de perfil quebrado.

\section{Los castillos-puerta de Bobastro}

Carecemos de una visión completa de lo que fue Bobastro desde un enfoque arqueológico, mucho menos de su red de castillos, torres y despoblados. Dado el desconocimiento que aún tenemos sobre la existencia y localización de los husụūn más inmediatos a la ciudad, recogemos aquí evidencias arqueológicas de seis de ellos, a fin de poder fundamentar las muchas diferencias que observamos con respecto a la edilicia desarrollada en la madina por los talleres ḥafșūníes.

De los textos se infiere que esa primera línea defensiva estaba formada por las fortalezas de Ṭalyayra, Šant Awlāliya (Santa Eulalia), Šant Mariyya (Santa María) y las alcazabas de Șuhayb. En línea con lo expuesto, la muestra seleccionada para desarrollar nuestro estudio arqueológico se acota a los hușūn en altura situados a menos de $3,5 \mathrm{~km}$ de la ciudad de Bobastro: cerro de Hornos, peñón de la Almona, castillejo de Mombicha (TM de Álora), castillón de los Gaitanes y Pico del Convento (TM de Ardales); a estos enclaves habremos de añadir la fortaleza que envuelve la conocida basílica semirrupestre, por las razones que próximamente se darán a conocer.

De las fuentes textuales se desprende que son enclaves inexpugnables situados en altura, motivo más que suficiente para dejar al margen algunas fortalezas menores situadas a bajas cotas, como la del puerto de las Atalayas (TM de Ardales) y la del cerro del cortijo de la Teja (TM de Álora), aunque formen parte esencial del dispositivo defensivo que protegía la madina (Fig. 1). Dejamos fuera también otros hușūn mucho más distantes, como las fortalezas de Ardales, Álora y el castillón de Peñarrubia, pues 
tampoco comparten las características formales y funcionales de los hușūn-abwāb (castillospuerta). Tampoco incluimos en la relación ciertos enclaves emirales cercanos, que más bien parecen puestos defensivos de escasa entidad, como los de Pedreras (TM de Álora) y Peñón del Moro (TM de Ardales).

Desde planteamientos arqueológicos, los ḥuṣūn$a b w a \bar{a} b$ citados en las fuentes escritas no son más que hușūn-refugio; aunque tienen algunas particularidades que merecen ser destacadas. En términos generales, podemos afirmar que son fortalezas de pequeño tamaño, cuyos recintos suelen cerrar en la peña rocosa, y no siempre ocupan la cota máxima (castillón de Gaitanes y cerro de Hornos), esto a diferencia de los muchos hușūn cercanos, que suelen alzarse sobre las cimas y cierran la totalidad de su perímetro con fábricas de mampostería (castillón de Peñarrubia, Sancti Petri, castillejos de Quintana, cerro de la Villa-Morototón).

La presencia de materiales romanos y tardoantiguos es una constante en estos asentamientos de altura inmediatos a Bobastro, y así se aprecia en el castillón de los Gaitanes, cerro de Hornos y Almona; si bien, el primero de ellos sólo presenta material constructivo y de modo residual, por lo que debe responder a prácticas de spoliae, en consonancia con los sillares de acarreo que se incorporan a los muros.

Entre los restos más significativos, cabe destacar que todos conservan aljibes tallados en roca, con la salvedad de la fortaleza de Mombicha, que es la situada a menor cota de altura y la más cercana a los recursos hídricos. Estos responden a la misma tipología y comparten el mismo sistema de impermeabilización: de planta ligeramente rectangular, con cordones alisados en sus cuatro ángulos y revestidos al interior con mortero hidráulico rico en cal y pintado a la almagra.

El hiṣn-bāb de mayor entidad y complejidad se documenta en cerro de Hornos, enclave que cuenta con un edificio significativo de cronología tardoantigua y emiral en su vertiente septentrional. En este sector se advierte una alta concentración de tégulas y son frecuentes los estucos de yeso con decoración pintada, junto a fragmentos de placas cerámicas decoradas a molde, posiblemente insertadas en los casetones de alguna techumbre. Destaca también su necrópolis inmediata y el singular conjunto de aljibes, uno de ellos con escalera tallada y planta cuadrangular, similar a las piscinas bautismales de época altomedieval documentadas en el norte peninsular.

Con todo, la edilicia militar de los hușūn-abwāb no presenta diferencias con la descrita para los hușūn-refugio. Son fábricas de mampostería desordenada extraída a pie de obra y tomada con morteros de barro, a diferencia de la arquitectura hafșūní de la que venimos hablando. Sólo cabe matizar ciertas diferencias en el castillón de los Gaitanes y en el castillejo de Mombicha, donde se aprecian hiladas muy desiguales pero tendentes a la horizontalidad, y se emplea una argamasa de cal excelente.

\section{Conclusiones}

Sobre el cerro del Castillón (Mesas de Villaverde - Ardales) se superponen dos palacios de estética emiral enteramente levantados con sillería, material noble y de prestigio. Son fábricas de influencia omeya, representativas del poder y precursoras de Madīnat al-Zahrā', de las cuales podemos extraer conclusiones cronológicas que vendrían a coincidir con el desarrollo de los acontecimientos históricos.

Entre las evidencias recientes del primer palacio ḥafșūní, como resultado de este estudio, se descubren elementos estructurales y ornamentales que derivan de la tradición clásica ${ }^{3}$, pero son ajenos y desconocidos por las estructuras locales de la zona, debiendo responder al influjo del modelo sirio-bizantino, tal vez producto de talleres cordobeses. Todo hace indicar que la arquitectura preislámica no va a pervivir entre las estructuras locales a finales del siglo IX. De hecho, la tradición constructiva clásica se pierde durante el periodo tardoantiguo, siendo imperceptible en el registro arqueológico, tal vez por no existir un poder centralizado que se manifieste en ambientes rurales, más si cabe en zonas de alta montaña poco o nada urbanizadas, prácticamente aisladas, inaccesibles y alejadas de los grandes centros de poder.

En contraste con los estudios publicados, las 
producciones arquitectónicas que observamos en Bobastro encuentran fácil encaje en el modelo explicativo propuesto para el centro y norte peninsular por Luis Caballero Zoreda (1994); con lo cual se abren nuevas perspectivas de interpretación hasta ahora no tenidas en cuenta.

\section{Notas}

${ }^{1}$ No vemos apropiado emplear el término "Iglesia de la Ciudad", más bien todo lo contrario, dado que se sitúa en el interior de un recinto militar aislado de ésta y vedado a la población. Sus exiguas dimensiones tampoco se adecuan a la entidad demográfica del yacimiento, por tanto cabe otorgarle un uso "cortesano" más restringido. Existen otros indicadores que respaldan su naturaleza palatina, pues comparte con el alcázar el mismo lenguaje constructivo, ya sea en su fábrica de sillares aparejados a soga, sus pavimentos hidráulicos pintados a la almagra para el interior o sus pavimentos con sillares de piedra calcarenita para el exterior. Iglesia y alcázar forman un grupo homogéneo de características técnicas similares, y deben responder a un proyecto unitario diseñado para todo el complejo, pues ambos edificios comparten el mismo sistema de producción y los mismos conocimientos técnicos.

${ }^{2}$ Las tres fases edilicias detectadas por Mergelina en su excavación arqueológica bien pueden corresponderse con las emprendidas por Ibn Hafșūn, Abd al-Raḥmān III y posiblemente los hammūdíes.

${ }^{3}$ En relación a la tradición o innovación en la arquitectura religiosa de Bobastro se ofrecen algunas claves para el debate historiográfico en el trabajo de F. Arce (2001, pp. 134-142) partiendo de los estudios publicados sobre la basílica semirrupestre.

\section{Bibliography}

Acién Almansa, M. (1997). Entre el Feudalismo y el Islam. Umar Ibn Hafsún en los historiadores, en las fuentes y en la historia, Universidad, Jaén.

Arce Sainz, F. (2001). "Arquitectura y rebelión: construcción de iglesias durante la revuelta de “Umar B. Ḥafșūn”, Al-Qantara, 22, 1, pp. 121-145.

Bermúdez Cano, J.M. (2004). "Capiteles precalifales en el palacio mudéjar del rey Don Pedro: tipos, talleres y reempleo", Romula, 3, pp. 257-284.

Caballero Zoreda, L. (1994). "Un canal de transmisión de lo clásico en la Alta Edad Media Española. Arquitectura y Escultura de influjo omeya en la Península Ibérica entre mediados del siglo VIII e inicios del siglo X”, al Qanta$r a, 15$ (2), pp. 321-348.

Gurriarán, P. (2004). "Hacia una construcción del poder. Las prácticas edilicias en la periferia andalusí durante el califato", Cuadernos de Madinat al-Zahra, 5, pp. 297-325.

León-Muñoz, A. (2018). "Técnicas constructivas mixtas en piedra en la Córdoba omeya”, Arqueología de la Arquitectura, 15, e078, in https://doi. org/10.3989/arq.arqt.2018.022.

Martínez Enamorado, V. (2012). Umar Ibn Hafsun. De la rebeldía a la construcción de la Dawla. Estudios en torno al rebelde de al-Andalus (880-928), Costa Rica.

Mergelina, C. de. (1927). Bobastro. Memoria de las excavaciones realizadas en las Mesas de Villaverde. El Chorro (Málaga), Junta Superior de Excavaciones y Antigüedades, 89, Madrid.

Navarro Palazón, J. (2005). "Sobre Palacios Andalusíes (Siglos XII-XIV)". Vivir en palacio en la Edad Media. Siglos XII - XV, Segovia, pp. 111-144.

Puertas Tricas, R. (2006). Iglesias rupestres de Málaga, Málaga.

Vallejo Triano, A. (2010). La ciudad califal de Madinat al-Zahra. Arqueología de su arquitectura, Sevilla 